\title{
Active Role of Glutamate Uptake in the Synaptic Transmission from Retinal Nonspiking Neurons
}

\author{
Ko Matsui, Nobutake Hosoi, and Masao Tachibana \\ Department of Psychology, Graduate School of Humanities and Sociology, The University of Tokyo, Tokyo \\ 113-0033, Japan
}

\begin{abstract}
We examined the role of glutamate uptake in the synaptic transmission of graded responses from newt retinal bipolar cells (BCs) to ganglion layer cells (GLCs). In dissociated Müller cells (retinal glia), glutamate evoked an uptake current that was effectively inhibited by L-trans-pyrrolidine-2,4-dicarboxylic acid (PDC). PDC had no effect on the non-NMDA receptors of dissociated spiking neurons. In the retinal slice preparation, dual whole-cell recordings were performed from a pair of $\mathrm{BC}$ and GLC. A depolarizing pulse applied to a BC activated the $\mathrm{Ca}^{2+}$ current $\left(I_{\mathrm{Ca}}\right)$ in the BC and evoked an EPSC in the GLC. Application of PDC prolonged both non-NMDA and NMDA receptor-mediated components of the evoked EPSC but changed neither the amplitude nor time course of $I_{\mathrm{Ca}}$. When the slice preparation was superfused with a solution containing glutamate but not PDC, the evoked EPSC decreased in amplitude without changing the time course, suggesting that the
\end{abstract}

In synapses in which spikes trigger glutamate release, the slow decay $(>100 \mathrm{msec})$ of the NMDA receptor-mediated EPSC (NMDA-EPSC) is determined mainly by the channel kinetics, which are much slower than the decrease of glutamate in the synaptic cleft (Lester et al., 1990). On the other hand, it is unclear what determines the rapid decay of the non-NMDA receptormediated EPSC (non-NMDA-EPSC), because the time course of glutamate release (Diamond and Jahr, 1995), the rate of glutamate clearance (Clements, 1996), and the deactivation and desensitization rate of non-NMDA receptors (Jones and Westbrook, 1996) all fall into the order of a few milliseconds.

Glutamate extrusion from the synaptic cleft seems to rely entirely on passive diffusion and uptake by glutamate transporters. However, it is still not known whether uptake speeds up the clearance rate of glutamate fast enough to alter the shape of EPSCs. Some papers report that blockade of glutamate uptake may retard glutamate clearance from the synaptic cleft, but the time course of the spike-induced non-NMDA-EPSC is determined primarily by the properties of non-NMDA receptors (Isaacson and Nicoll, 1993; Sarantis et al., 1993). These results

Received April 7, 1999; revised May 25, 1999; accepted May 27, 1999.

This work was supported by a Grant-in Aid for Scientific Research 09480238 from The Ministry of Education, Science, Sports, and Culture to M.T. K.M. is a research fellow of Japan Society for Promotion of Science. We thank Lawrence H. Pinto for critical reading of this manuscript, and Naotoshi Minami and Ken Berglund for excellent technical assistance on dissociation and recordings from isolated retinal cells.

Correspondence should be addressed to Masao Tachibana, Department of Psychology, Graduate School of Humanities and Sociology, The University of Tokyo, 7-3-1 Hongo, Bunkyo-ku, Tokyo 113-0033, Japan.

Copyright (c) 1999 Society for Neuroscience 0270-6474/99/196755-12\$05.00/0 prolongation of the evoked EPSC is not attributable to a simple increase in ambient glutamate concentration after inhibition of glutamate uptake. Because PDC did not affect the amplitude, time course, or frequency of spontaneous EPSCs, it is unlikely that PDC modified presynaptic and/or postsynaptic mechanisms. These results indicate that inhibition of glutamate uptake slows the clearance of glutamate accumulated in the synaptic cleft by multiple quantal release and prolongs the evoked EPSC. The role of glutamate uptake at synapses in the inner retina is not only to maintain the extracellular glutamate concentration at a low level but also to terminate the light-evoked EPSCs rapidly.

Key words: retina; bipolar cell; ganglion cell; Müller cell; synaptic transmission; glutamate; uptake; transporter; nonNMDA receptor; NMDA receptor; EPSC; spontaneous EPSC suggest that glutamate uptake may be important only for maintaining the glutamate concentration at a low level in the synapses in which spikes trigger transmitter release.

Retinal bipolar cells (BCs) are nonspiking neurons and respond to photo stimulation in a graded manner (Saito and $\mathrm{Ku}$ jiraoka, 1982). The amount of glutamate release from the terminal of BC increases as the duration of depolarizing pulses is prolonged up to a few hundred milliseconds (Sakaba et al., 1997). Using the retinal slice preparation, we have demonstrated that a depolarizing pulse applied to a single BC evokes an EPSC in a synaptically connected ganglion layer cell (GLC) (Matsui et al., 1998). The EPSC consists of a rapidly activated non-NMDAEPSC and a slowly activated NMDA-EPSC. With increasing the duration of depolarizing pulses applied to the $\mathrm{BC}$, the nonNMDA-EPSC desensitizes substantially, whereas the NMDAEPSC is prolonged. These results indicate that synaptically released glutamate remains elevated for awhile and suggest that uptake by glutamate transporters may be of particular importance in determining the decay time course of the evoked EPSC in GLCs.

Using the retinal slice preparation, we investigated whether inhibitors of glutamate uptake affect the shape of the evoked and spontaneous EPSCs in GLCs. We found that introduction of uptake inhibitors slowed the decay of the evoked non-NMDAEPSC and NMDA-EPSC but not the spontaneous EPSC, which consisted only of a non-NMDA component. These results indicate that, at synapses formed between BC and GLC in the retina, glutamate uptake has an active role in the clearance of glutamate and shapes the time course of EPSCs evoked by single depolarizing pulses. 


\section{MATERIALS AND METHODS}

Recordings from the retinal slice preparation. GLCs consist of ganglion cells and displaced amacrine cells (Ball and Dickson, 1983). As stated in our previous paper (Matsui et al., 1998), the two cell types could not be readily classified in the newt (Cynops pyrrhogaster) retinal slice preparation with the morphology, the light response, or the membrane current properties. In the present study, we did not distinguish between amacrine and ganglion cells.

Whole-cell patch recordings were made from either synaptically connected BC and GLC pairs or GLCs alone. Procedures for preparing the newt retinal slices were met by the guidelines of the Physiological Society of Japan and have been described in detail previously (Matsui et al., 1998).

The slices were superfused continuously with the oxygenated control solution $\mathrm{S} 1$ (in mM): $110 \mathrm{NaCl}, 2 \mathrm{KCl}, 2 \mathrm{CaCl}_{2}, 1 \mathrm{MgCl}_{2}, 5$ glucose, and 5 HEPES titrated to $\mathrm{pH} 7.8$ with $\mathrm{NaOH}$. Picrotoxin $(200 \mu \mathrm{M})$ and strychnine $(10 \mu \mathrm{M})$ (both from Sigma, St. Louis, MO) were added to S1 to block the activation of GABA and glycine receptors, respectively. $\mathrm{D}(-)$-2-Amino-5-phosphonopentanoic acid (D-AP-5) $(50 \mu \mathrm{M})$ was also included to isolate the non-NMDA receptor-mediated current in most of the experiments. When the NMDA receptor-mediated current was monitored, either $5 \mu \mathrm{M}$ 6-nitro-7-sulfamoylbenzo[F]quinoxaline-2,3-dione (NBQX) or $10 \mu \mathrm{M}$ 6-cyano-7-nitroquinoxaline-2,3-dione (CNQX) was substituted for D-AP-5. D-AP-5, NBQX, CNQX, L- trans-pyrrolidine-2,4dicarboxylic acid (PDC), and L(-)-threo-3-hydroxyaspartic acid (THA) were purchased from Tocris Cookson (Bristol, UK).

The pipette solution for $\mathrm{BC}$ recordings consisted of $\mathrm{P} 1$ (in $\mathrm{mM}$ ): 84 $\mathrm{CsCH}_{3} \mathrm{SO}_{4}, 4 \mathrm{CsCl}, 10$ TEA-Cl, $5.5 \mathrm{MgCl}_{2}, 0.2$ BAPTA, 20 HEPES, 5 ATP disodium salt, and 0.5 GTP trisodium salt. The pipette solution for GLC recordings consisted of $\mathrm{P} 2$ (in $\mathrm{mM}$ ): $65-70 \mathrm{CsCH}_{3} \mathrm{SO}_{4}, 3 \mathrm{CsCl}, 5$ CsF, 10 TEA-Cl, $5.5 \mathrm{MgCl}_{2}, 0.5 \mathrm{CaCl}_{2}, 5$ EGTA, $20 \mathrm{HEPES}$, and 5 ATP. Both solutions were titrated to $\mathrm{pH}$ 7.7-7.8 with $\mathrm{CsOH}$ and supplemented with $0.25 \%$ Lucifer yellow $\mathrm{CH}$ dipotassium salt. Liquid junction potentials were corrected for all recordings.

BCs and GLCs were whole-cell voltage-clamped with two EPC-7 (List, Darmstadt, Germany) patch-clamp amplifiers. Current records were typically low-pass filtered at $1 \mathrm{kHz}$ and digitized at $5 \mathrm{kHz}$. The fast capacitance compensation was adjusted to cancel the transient current caused by the pipette capacitance. The series resistance was between 20 and $50 \mathrm{M} \Omega$ but was not compensated.

Rundown of the evoked EPSC was relatively fast (10-30 min) after the whole-cell clamp configuration was established. Because the glutamateevoked current in GLCs and the light-induced current in both BCs and GLCs lasted for $>1 \mathrm{hr}$, the postsynaptic mechanisms of cells under voltage clamp would not be responsible for the rapid rundown of the evoked EPSC. Rapid rundown of transmitter release has been reported in isolated goldfish BCs (Minami et al., 1998). This rapid rundown allowed us to exchange only a couple of bath solutions to be tested for each cell pair.

The retinal slices were set in a light-tight Faraday cage and observed under the microscope equipped with infrared (IR) illumination and an IR-sensitive camera. To photostimulate the retinal slices, a white light, the intensity of which ranged between 0.5 and 5 lux at the position of the retinal slice, was applied through the condenser lens of the microscope. The light-evoked responses were very well preserved in all cell types under these conditions, although the retinal slices were prepared under room light. Recordings were done within $2 \mathrm{hr}$ after preparation of the slices.

Cell types were identified by their light-evoked responses and morphology, which was visualized by Lucifer yellow staining after the recording. Whether presynaptic ON-type BC or OFF-type BC was stimulated, there were no significant differences in the evoked EPSCs recorded from the synaptically connected GLCs. The light-evoked responses of GLCs were usually of ON/OFF-transient type. Thus, all data shown here were obtained from pairs of an ON-type or OFF-type BC and an ON/OFF-transient type GLC.

Dissociation of retinal cells. Müller cells and spiking neurons were dissociated from the newt retina with the similar procedures described by Tachibana and Okada (1991). The isolated retinas were treated with a low- $\mathrm{Ca}^{2+}$ solution containing hyaluronidase $(0.1 \mathrm{mg} / \mathrm{ml}$; Sigma) and then with cysteine (5 mM; Wako Pure Chemical, Tokyo, Japan)-activated papain $\left(30-50 \mathrm{mg} / \mathrm{ml}\right.$; Wako). The low- $\mathrm{Ca}^{2+}$ solution contained (in mM): $120 \mathrm{NaCl}, 2.6 \mathrm{KCl}, 1 \mathrm{NaHCO}_{3}, 0.5 \mathrm{NaH}_{2} \mathrm{PO}_{4}, 1$ NaPyruvate, 4 HEPES, and 16 glucose titrated to $\mathrm{pH} 7.2$ with $\mathrm{NaOH}$. The retinas were rinsed with the control saline (S1) several times and then mechanically triturated with a glass pipette.

Recordings from isolated cell preparation. Müller cells could be readily identified by their characteristic morphology (Schwartz and Tachibana, 1990; Barbour et al., 1991). The intracellular solution for Müller cell recordings consisted of either $\mathrm{P} 2$ or $\mathrm{P} 3$ (in $\mathrm{mM}$ ): $95 \mathrm{KCl}, 5 \mathrm{NaCl}, 7$ $\mathrm{MgCl}_{2}, 1 \mathrm{CaCl}_{2}, 5$ EGTA, 5 HEPES, and 5 ATP titrated to $\mathrm{pH} 7.0$ with $\mathrm{KOH}$. External solution contained either S1, the control saline, or S2 (in $\mathrm{mm}$ ): $105 \mathrm{NaCl}, 2.5 \mathrm{KCl}, 3 \mathrm{CaCl}_{2}, 0.5 \mathrm{MgCl}_{2}, 6 \mathrm{BaCl}_{2}, 15$ glucose, and 5 HEPES titrated to $\mathrm{pH} 7.3$ with $\mathrm{NaOH}$. $\mathrm{Ba}^{2+}$ was included in $\mathrm{S} 2$ to block the anomalous rectifier $\mathrm{K}^{+}$channels in Müller cells (Barbour et al., 1991). $\mathrm{P} 2$ and $\mathrm{S} 1$ were used for the experiment shown in Figure $1 A$, and $\mathrm{P} 3$ and S2 were used for the experiments shown in Figure 1, $B-E$.

Amacrine and ganglion cells are the only neurons known to generate $\mathrm{Na}^{+}$action potentials in the retina. Isolated cells were identified as spiking neurons when a large (more than a few hundred picoamperes) and rapid (decay time constant less than a few milliseconds) $\mathrm{Na}^{+}$current was evoked by a depolarizing pulse under voltage clamp. For recordings from spiking neurons, the pipette and external solutions were P2 and S1, respectively.

\section{RESULTS}

\section{Glutamate uptake and its inhibition by PDC in isolated Müller cells}

Müller cells are the predominant type of glial cells in the vertebrate retina. Their processes fill much of the extracellular space, and they envelope somas and processes of all retinal neurons (Dowling, 1987). Fine processes of Müller cells extend through the inner plexiform layer (IPL) in which BCs make synaptic contact with ganglion and amacrine cells. Because Müller cells are known to possess glutamate transporters in various species (Brew and Attwell, 1987; Schwartz and Tachibana, 1990; Eliasof et al., 1998; Harada et al., 1998; Rauen et al., 1998), these transporters may contribute to the clearance of glutamate in the IPL. We first examined physiologically whether the glutamate transporters are actually present in Müller cells of the newt retina.

Müller cells dissociated from the newt retina were voltageclamped in the whole-cell recording configuration. To block possible activation of ionotropic glutamate receptors, $5 \mu \mathrm{M}$ NBQX and $50 \mu \mathrm{M}$ D-AP-5 were included in both the bath and puff solutions. When glutamate (1 mM) was applied via a puff pipette, a large inward current was evoked in the Müller cell held at -80 $\mathrm{mV}$. When the holding potential was shifted positively, the response decreased in amplitude without changing its polarity (Fig. 1A).

The current-voltage $(I-V)$ relationship was derived from the difference between the response to voltage ramps in the presence and absence of $1 \mathrm{~mm}$ glutamate (Fig. $1 B$, Glu). In this example, glutamate was applied via a Y-tube microflow system (Suzuki et al., 1990) to reach rapidly a constant concentration. The $I-V$ relationship showed strong inward rectification, and no obvious outward current was observed, even at large positive potentials. These properties are similar to those of the glutamate transporter current reported in other species (Schwartz and Tachibana, 1990; Barbour et al., 1991).

Various concentrations of glutamate were applied to examine the affinity of glutamate to the transporter (Fig. 1C, top). The dose-response curve was obtained, and the Michaelis-Menten equation was fitted to the data (Fig. $1 D$, top). The value of apparent $K_{\mathrm{m}}$ for glutamate $\left(K_{\mathrm{Glu}}\right)$ was $10.8 \mu \mathrm{M}(n=16)$, which is similar to the value reported in Müller cells of the tiger salamander retina (19.8 $\mu \mathrm{M})$ (Barbour et al., 1991).

Because our strategy was to compare the time course of the evoked and spontaneous EPSCs before and after the blockade of 


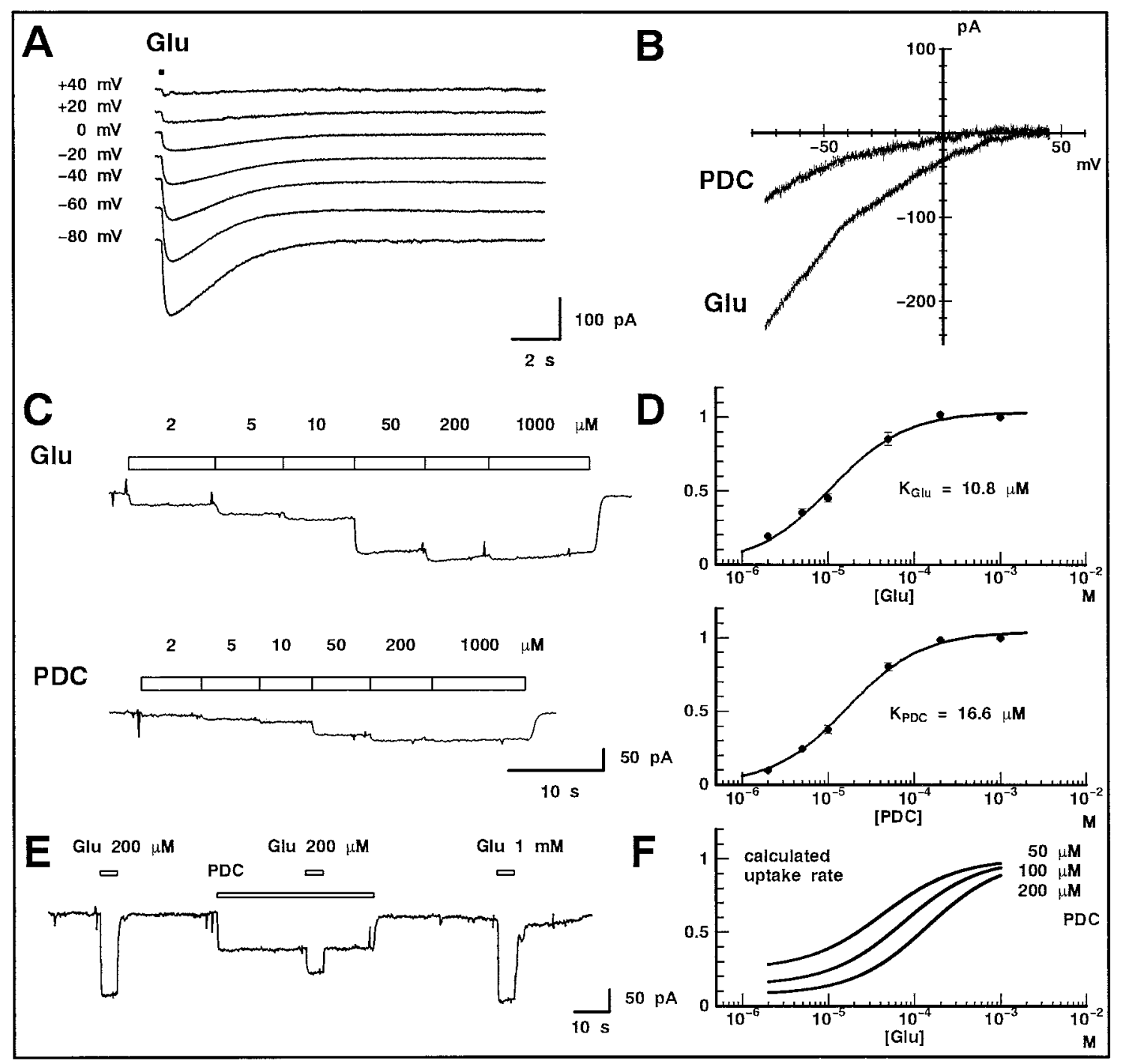

Figure 1. PDC blocked glutamate uptake in Müller cells isolated from the newt retina. $A$, Glutamate (1 mM) was puff applied (100 msec; timing indicated as the bar at the top) to a Müller cell that was whole-cell voltage-clamped at various potentials (noted on the left). The glutamate-induced uptake current did not reverse its polarity at positive potentials. $B, I-V$ curves obtained in the presence of $1 \mathrm{~mm}$ glutamate $(G l u)$ and $200 \mu \mathrm{M}$ PDC. Membrane currents were measured by applying voltage ramps $(130 \mathrm{mV} / 300 \mathrm{msec})$. Each $I-V$ curve was derived from the difference between the average of three current traces in the presence and absence of the chemicals, which were applied via the Y-tube microflow system. $C$, The uptake currents induced by various concentrations (top) of glutamate $(G l u)$ or PDC. Both traces were obtained from the same cell voltage-clamped at $-75 \mathrm{mV}$. D, Dose-response curves for glutamate (top panel) or PDC (bottom panel). Means \pm SEM are illustrated (pooled data from 16 cells). Data points were fitted by the Michaelis-Menten equation. $E$, Inhibition of the glutamate-induced uptake current by PDC (200 $\mu \mathrm{M})$. The concentration of glutamate $(G l u)$ was $200 \mu \mathrm{M}$ (left and middle) and $1 \mathrm{~mm}$ (right). The cell was held at $-75 \mathrm{mV} . F$, Estimation of the uptake rate of glutamate in the presence of PDC. A simple competitive inhibition model was used with the values of $K_{\mathrm{Glu}}$ and $K_{\mathrm{PDC}}$ obtained in $D$. The concentration of PDC is shown at the right of the curves.

the glutamate transporter, it was essential to understand the properties of its blocker. PDC is known to bind with high-affinity glutamate transporters (Bridges et al., 1991). Therefore, PDC may compete with glutamate in binding and may be subsequently transported at a slower rate than glutamate, resulting in a reduction of the uptake rate of glutamate (Sarantis et al., 1993). When PDC $(200 \mu \mathrm{M})$ was applied alone to Müller cells, an inward current was induced. The $I-V$ relationship was similar in shape to that of glutamate, but the amplitude was consistently smaller (Fig. $1 B, P D C)$. The working range of PDC was similar to that of glutamate (Fig. $1 C$, bottom). Apparent $K_{\mathrm{m}}$ for PDC $\left(K_{\mathrm{PDC}}\right)$ was $16.6 \mu \mathrm{M}(n=16)$ (Fig. $1 D$, bottom).

We next examined how PDC inhibited the glutamate uptake. PDC $(200 \mu \mathrm{M})$ induced an inward current (Fig. 1E, PDC), which was $40.8 \pm 2.4 \%$ (pooled data are expressed as mean \pm SEM for this and all subsequent data; $n=3$ ) of the current evoked by a saturating dose of glutamate (Fig. $1 E$, Glu $1 \mathrm{~mm}$ ). Addition of glutamate $(200 \mu \mathrm{M})$ to PDC $(200 \mu \mathrm{M})$ evoked a small response (Fig. 1E). The glutamate-induced current reduced to $44.3 \pm 2.8$ (1 mM glutamate) and $26.6 \pm 1.3 \%(200 \mu \mathrm{M}$ glutamate $)$ of its control value (application of $1 \mathrm{~mm}$ glutamate alone). With the values of $K_{\mathrm{Glu}}$ and $K_{\mathrm{PDC}}$ obtained above, the currents evoked by $1 \mathrm{~mm}$ and $200 \mu \mathrm{M}$ glutamate are estimated to be reduced by 200 $\mu \mathrm{M}$ PDC to 54.6 and $36.6 \%$, respectively (Sarantis et al., 1993). These estimated values are similar to the values obtained experimentally.

Using a simple competitive inhibition model (Sarantis et al., 1993), we estimated the extent to which PDC reduced the rate of 


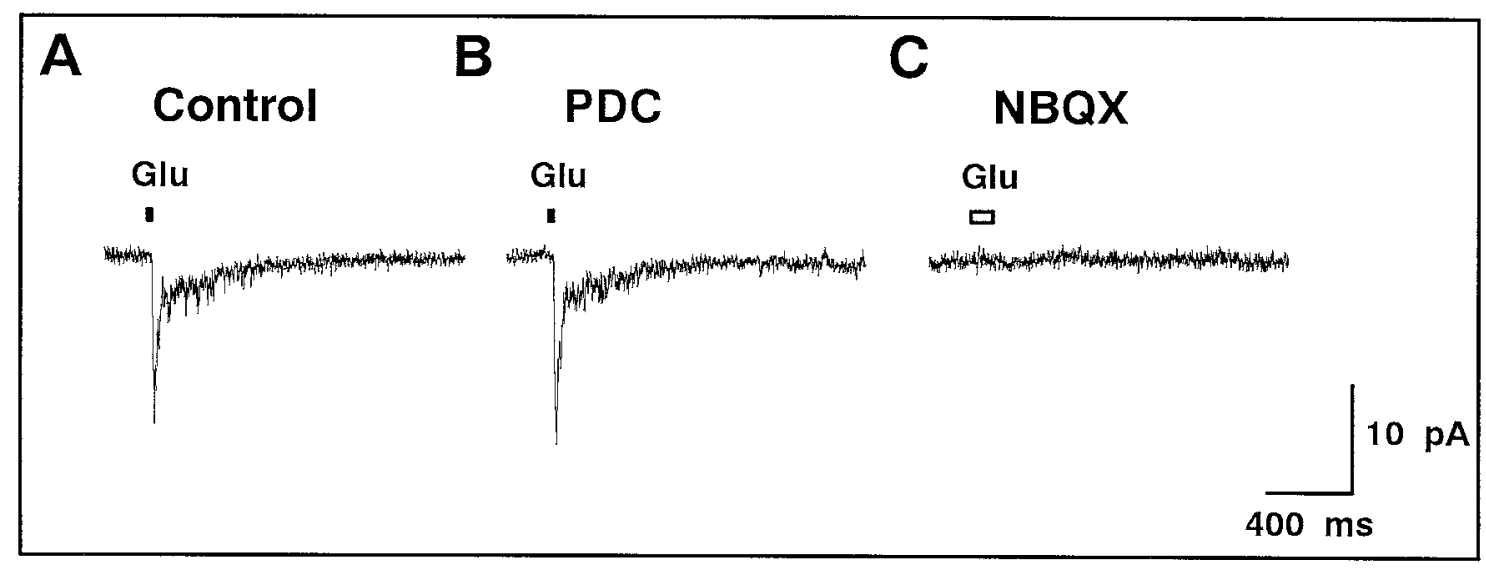

Figure 2. The current through non-NMDA receptors was not affected by PDC. $A$, A spiking neuron isolated from the newt retina was voltage-clamped at $-80 \mathrm{mV}$. Both the superfusate and the puff pipette solution included $50 \mu \mathrm{M}$ D-AP-5 to block the current through NMDA receptors. A 20 msec puff-application (top) of $200 \mu \mathrm{M}$ glutamate (Glu) induced an inward current. B, The glutamate-induced current was not affected by the presence of 200 $\mu \mathrm{M}$ PDC. $C$, Application of NBQX $(5 \mu \mathrm{M})$ to the superfusate completely blocked the response to a 100 msec puff of glutamate.

glutamate uptake. The curves shown in Figure $1 F$ indicate the relative rate of glutamate uptake in the presence and absence of PDC. With $200 \mu \mathrm{M}$ PDC, the uptake rate is reduced to $88.6(1 \mathrm{mM}$ glutamate) and $61.8 \%$ (200 $\mu \mathrm{M}$ glutamate) of control at the steady state. In the slice preparation, the concentration of PDC may be somewhat lower at the synaptic cleft than in the bath, because PDC itself is taken up by the glutamate transporters. This may reduce the effectiveness of $\mathrm{PDC}$ in inhibiting the glutamate uptake.

\section{No effect of PDC on non-NMDA receptors of isolated spiking neurons}

Because glutamate and PDC have similar affinity to the glutamate transporters (Fig. 1), high concentrations of PDC may be required to inhibit uptake of a high concentration of glutamate $(\sim 1 \mathrm{~mm})$, which is estimated to be reached in the synaptic cleft (Clements et al., 1992). To use PDC as a selective inhibitor of glutamate uptake, it is essential to confirm that a high concentration of PDC has little effect on glutamate receptors. Therefore, we examined whether PDC had a direct effect on the non-NMDA receptors of spiking neurons isolated from the newt retina. To isolate nonNMDA receptor-mediated current, $50 \mu \mathrm{M}$ D-AP-5 (a specific blocker of NMDA receptors) was included in both the superfusate and the puff pipette solution.

Brief puff application of $200 \mu \mathrm{M}$ glutamate produced an inward current in an isolated spiking neuron maintained at $-80 \mathrm{mV}$ (Fig. $2 A)$. When PDC (200 $\mu \mathrm{M})$ was bath applied, the holding current remained the same and the glutamate-induced current did not change in amplitude or time course (Fig. $2 B$ ). The glutamateinduced current was completely abolished with addition of $5 \mu \mathrm{M}$ NBQX (a specific blocker of non-NMDA receptors) to the superfusate (Fig. 2C). Similar results were obtained from four spiking neurons. These results suggest that PDC has little or no effect on non-NMDA receptors of isolated spiking neurons.

\section{Enhancement of the glutamate-induced, non-NMDA receptor-mediated current in GLCs of the retinal slice by PDC}

We next examined the effect of PDC on the glutamate-induced, non-NMDA receptor-mediated current in GLCs of the retinal slice preparation. Synaptic inputs to GLCs were blocked by totally replacing divalent cations in the control superfusate with
$3 \mathrm{~mm} \mathrm{Co}^{2+}$. This concentration of $\mathrm{Co}^{2+}$ effectively blocks the $\mathrm{Ca}^{2+}$ current in BCs and subsequently suppresses the evoked EPSCs in GLCs (Matsui et al., 1998). In the present experiment, the blockade of synaptic transmission by $\mathrm{Co}^{2+}$ was confirmed by monitoring the photoresponses in GLCs; the photoresponses disappeared within a couple of minutes after the application of $\mathrm{Co}^{2+}$. D-AP-5 $(50 \mu \mathrm{M})$ was included in both the superfusate and the puff pipette solution. Glutamate $(200 \mu \mathrm{M})$ was applied briefly $(10-100 \mathrm{msec})$ via a puff pipette. The position of the pipette tip was adjusted along the IPL to find the "hot spot" of the voltageclamped GLC.

Puff-applied glutamate induced an inward current in GLC maintained at $-80 \mathrm{mV}$. The time course of the glutamateinduced current varied from cell to cell but was always slower than that observed in isolated cells. The slow time course may be caused by the delay of glutamate diffusion into the slice, and the variability may be caused by the distance between the glutamate receptors of a given voltage-clamped GLC and the surface of the slice preparation. When PDC $(200 \mu \mathrm{M})$ was added to the superfusate, the glutamate-induced current increased in both amplitude and decay time (Fig. $3 A$ ). The ratio of the peak amplitude with and without PDC was compared with the ratio of the total charge (i.e., the time integral of the glutamate-induced current) with and without PDC (Fig. 3B). The relative increase in total charge was always larger than the increase in amplitude, indicating that the glutamate-induced current was prolonged after application of PDC. We also measured the half-decay time of the glutamate-induced current, which should provide another measure of changes in time course. The half-decay time in the presence of PDC was always slower than that of the control (Fig. 3C).

Although a high concentration $(50 \mu \mathrm{M})$ of competitive antagonist D-AP-5 was included in both the superfusate and the puff pipette solution, inhibition of the glutamate uptake by PDC could have raised the glutamate concentration in the synaptic cleft to a level high enough to activate NMDA receptors, which have high affinity for glutamate. This possibility was examined by recording the glutamate-induced current at various command potentials in the presence of PDC (Fig. 3D). The current traces at all potentials tested (between -80 and $+40 \mathrm{mV}$ ) were superimposable after scaling (Fig. 3D, bottom traces). The $I-V$ relationship was linear 


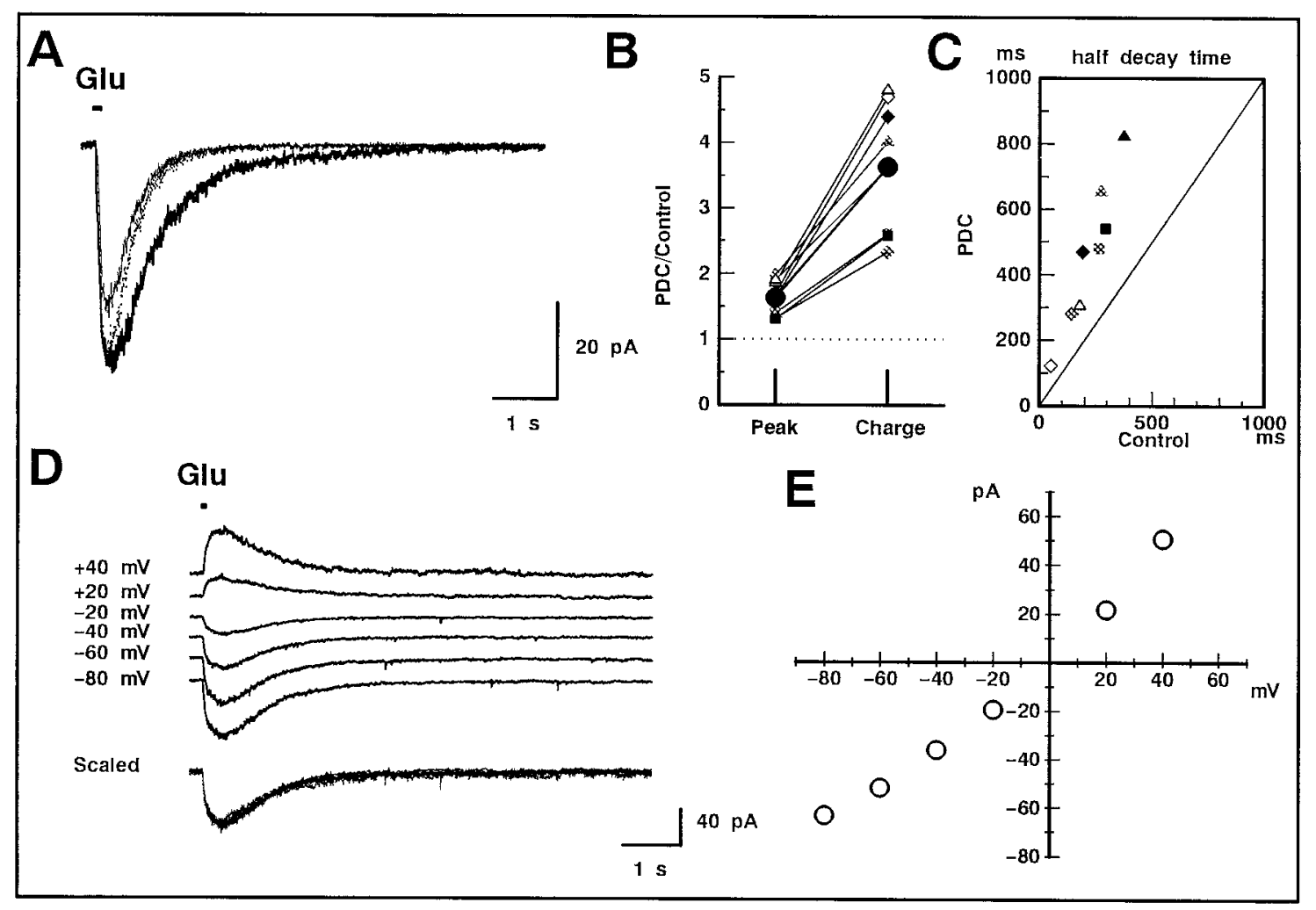

Figure 3. Effect of PDC on the non-NMDA receptor-mediated current in GLCs of the retinal slice. $A$, A GLC was voltage-clamped at $-80 \mathrm{mV}$, and glutamate $(200 \mu \mathrm{M})$ was puff applied for $100 \mathrm{msec}$. The tip of the puff pipette was carefully positioned above the IPL to evoke a large response. In both the bath and puff solutions, divalent cations were replaced with $\mathrm{Co}^{2+}$ to suppress the synaptic transmission, and D-AP-5 (50 $\mu \mathrm{M}$ ) was included to block the NMDA receptor-mediated current. The glutamate-induced current in the presence of $200 \mu \mathrm{M}$ PDC (thick trace) was larger in amplitude and decayed more slowly than control (thin trace). After scaling (dotted trace), it is clear that PDC prolonged the glutamate-induced current through non-NMDA receptors. $B$, Relative increase in the peak amplitude (Peak) and total charge (Charge) before and after the application of PDC. Data were obtained from three cells and are illustrated with different symbols. Duration of the puff was 10 (open), 50 (half-tone), or 100 ( filled) msec. The averaged values are shown with large filled circles. $C$, The scatter diagram illustrates the relationship between the half-decay time of the glutamate-induced current in the absence (Control) and presence of PDC. All symbols correspond to those shown in $B$. D, The current was evoked in a GLC by a $50 \mathrm{msec}$ puff of glutamate in the presence of $200 \mu \mathrm{M}$ PDC. The holding potential was changed to various values. The current traces are shifted arbitrarily for a better view. All of the current traces were superimposable after scaling (bottom traces). E, The peak amplitude of the glutamate-induced current was plotted against the command potential of GLC. The linear relationship confirmed that the glutamate-induced current was caused by the activation of non-NMDA receptors.

and reversed at $\sim 0 \mathrm{mV}$ (Fig. $3 E$ ). These results indicate that the NMDA component of the glutamate-induced current did not emerge in the presence of $200 \mu \mathrm{M}$ PDC and $50 \mu \mathrm{M}$ D-AP-5.

This series of control experiments indicates that the effects of PDC observed in GLCs of the slice preparation are not ascribable to changes in the postsynaptic mechanisms. Selective inhibition of glutamate transporters by PDC is consistent with the assumption that the enhanced amplitude of the response to puff-applied glutamate is caused by the increase in glutamate concentration reaching non-NMDA receptors of GLCs in the slice preparation. The prolonged time course of the glutamate-induced current could be also interpreted as a slowdown of glutamate extrusion by PDC.

\section{Enhancement of the light-evoked non-NMDA-EPSC by PDC}

In the previous section, the effect of PDC was evaluated by exogenously applying glutamate to the slice preparation. We next investigated the effect of PDC on the non-NMDA receptormediated response of GLC to endogenous transmitter.

When a full-field white light stimulus was applied to the retinal slice, an ON/OFF-transient response was evoked in the GLC voltage-clamped at $-80 \mathrm{mV}$ (Fig. 4A, Control). When $200 \mu \mathrm{M}$
PDC was bath applied, both ON and OFF transients were enhanced and their decay was prolonged (Fig. 4A, PDC). To relieve $\mathrm{Mg}^{2+}$ block of NMDA receptors (Nowak et al., 1984), the holding potential was shifted to $-40 \mathrm{mV}$, and the same light stimulus was applied. In the presence of PDC, the photoresponse at the holding potential of $-40 \mathrm{mV}$ (Fig. $4 B$, thin trace) was superimposable to that at $-80 \mathrm{mV}$ (Fig. $4 B$, thick trace) after scaling (Fig. $4 B$, dotted trace). Although the time course of the photoresponse was slow, unblocking of NMDA receptors could result in drastic changes of the response waveform at the holding potential of -40 $\mathrm{mV}$ (Mittman et al., 1990). Therefore, as was the case of exogenously applied glutamate (Fig. 3), $50 \mu \mathrm{M}$ D-AP-5 was strong enough to inhibit the NMDA component of the photoresponse, and no additional activation of NMDA receptors was unveiled with the addition of $200 \mu \mathrm{M}$ PDC. Similar results were obtained from three GLCs.

The onset delay of the $\mathrm{ON}$ transient was slightly increased by $17.5 \pm 8.7 \mathrm{msec}(n=6)$ after application of PDC (Fig. $4 A)$. This effect may be ascribed to the actions of PDC in the outer plexiform layer (OPL). In the OPL, light stimulation reduces the release of glutamate from photoreceptors. Thus, the blockade of glutamate transporters in the OPL by PDC would slow down the 


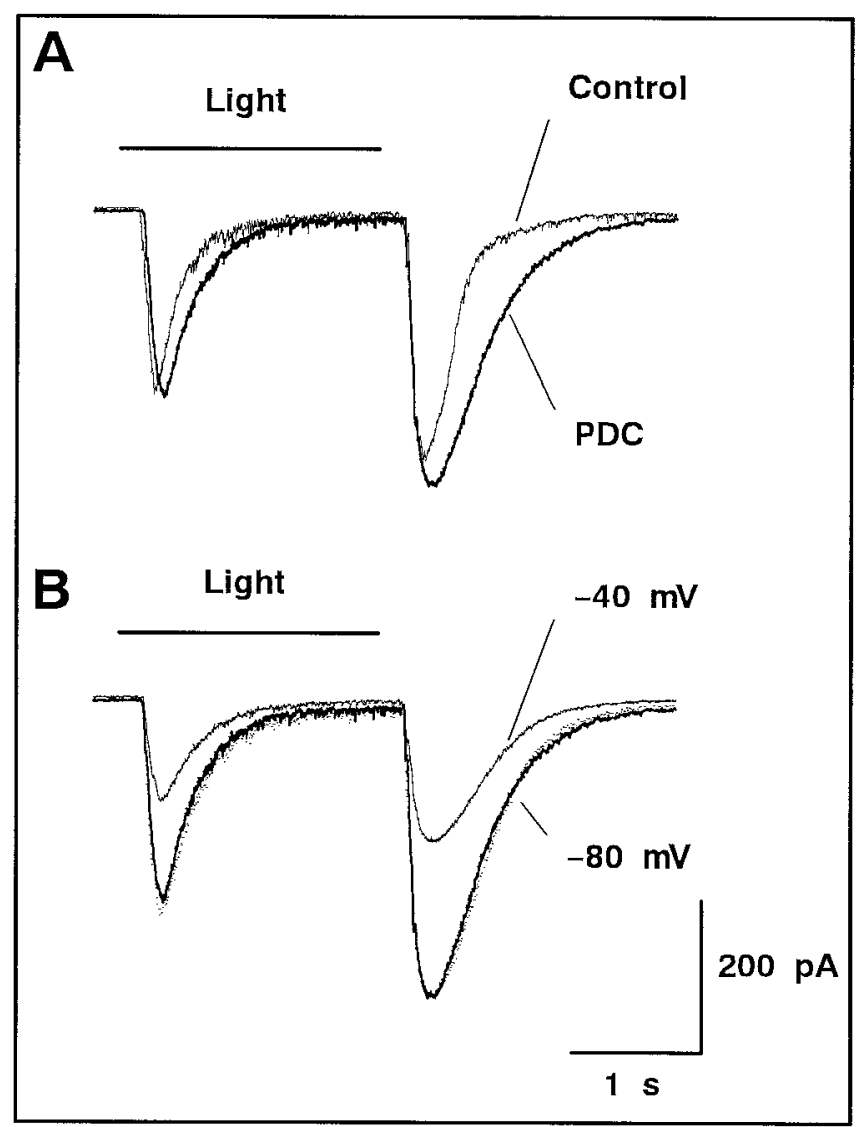

Figure 4. The light-evoked responses in GLC were enhanced by PDC. $A$, With full-field illumination (Light), an ON/OFF transient response (thin trace) was evoked in GLC of the retinal slice, which was superfused with the solution containing D-AP-5 $(50 \mu \mathrm{M})$. Both ON and OFF transients were prolonged by application of $200 \mu \mathrm{M}$ PDC (thick trace). GLC was held at $-80 \mathrm{mV}$. B, The photoresponses were recorded in the presence of PDC. The holding potential was set at -80 (thick trace) and -40 (thin trace) $\mathrm{mV}$. After scaling (dotted trace), both traces were superimposable, indicating that the NMDA receptor-mediated current was not emerged by application of PDC.

uptake of glutamate released from photoreceptors (Gaal et al., 1998), resulting in the slow onset of depolarization in ON-type bipolar cells, which would in turn cause the onset delay of the ON transient in GLCs.

\section{Prolongation of the evoked non-NMDA-EPSC in GLCs of the retinal slice by PDC}

In the previous section, it was confirmed that synaptic input to GLC was enhanced by PDC. However, it is difficult to identify the sites of PDC action because glutamate mediates synaptic transmission in both the OPL and IPL. Therefore, we performed dual whole-cell recordings from BC and GLC pairs to investigate how PDC enhanced the synaptic transmission in the IPL. Depolarization of a single BC activates both non-NMDA and NMDA receptors of a synaptically connected GLC (Matsui et al., 1998). In this section, we focused on the non-NMDA component of the evoked EPSC. The NMDA component was suppressed by D-AP-5 $(50 \mu \mathrm{M})$ in the bath solution.

A BC was depolarized from the holding potential of -68 to -8 $\mathrm{mV}$ for $50 \mathrm{msec}$. A sustained inward current was induced in BC, and an evoked EPSC (peak amplitude, $16.6 \pm 3.5 \mathrm{pA} ; n=6$ ) was recorded from GLC voltage-clamped at $-80 \mathrm{mV}$ (Fig. $5 A$, thin

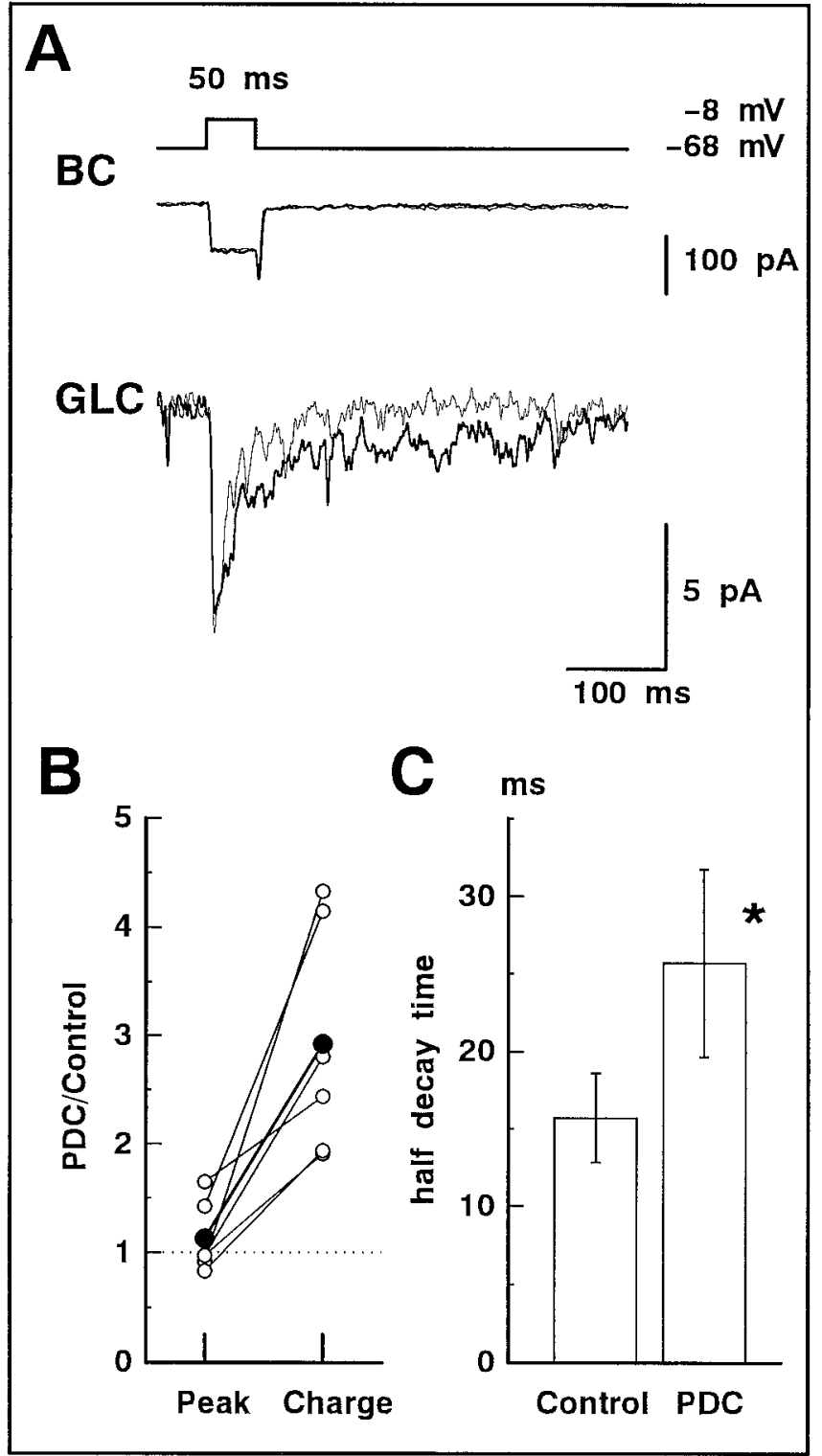

Figure 5. The evoked non-NMDA-EPSC was prolonged by PDC. $A, \mathrm{~A}$ $50 \mathrm{msec}$ depolarizing pulse (from -68 to $-8 \mathrm{mV}$; top) applied to $\mathrm{BC}$ activated $I_{\mathrm{Ca}}$ (middle; thin trace) in BC and evoked non-NMDA-EPSC in GLC voltage-clamped at $-80 \mathrm{mV}$ (bottom; thin trace). After application of $200 \mu \mathrm{M}$ PDC, neither the amplitude nor time course of $I_{\mathrm{Ca}}$ (thick trace) was affected, but the decay of the non-NMDA-EPSC was significantly prolonged (thick trace). D-AP-5 $(50 \mu \mathrm{M})$ was included in the bath solution. The current traces of $\mathrm{BC}$ for this and the subsequent figures are shown after leak subtraction. B, Relative increase in the peak amplitude (Peak) and total charge (Charge) of the evoked non-NMDA-EPSC before and after application of PDC. Data were obtained from six cell pairs. The averaged values are shown by large filled circles. $C$, The half-decay time of the evoked non-NMDA-EPSC in the absence (Control) and presence of PDC. Asterisks in this and subsequent figures indicate that the difference is statistically significant $(p<0.05)$. Data were obtained from six cell pairs.

line). The inward current in the $\mathrm{BC}$ has been demonstrated to be a $\mathrm{Ca}^{2+}$ current $\left(I_{\mathrm{Ca}}\right)$ (Matsui et al., 1998). When PDC $(200 \mu \mathrm{M})$ was bath applied, the peak amplitude of $I_{\mathrm{Ca}}$ did not change significantly (control, $63.4 \pm 6.2 \mathrm{pA}$; PDC, $62.1 \pm 6.6 \mathrm{pA} ; n=13$; $p=0.55$; levels of statistical significance were determined using paired Student's $t$ tests), but the decay of the evoked EPSC was 


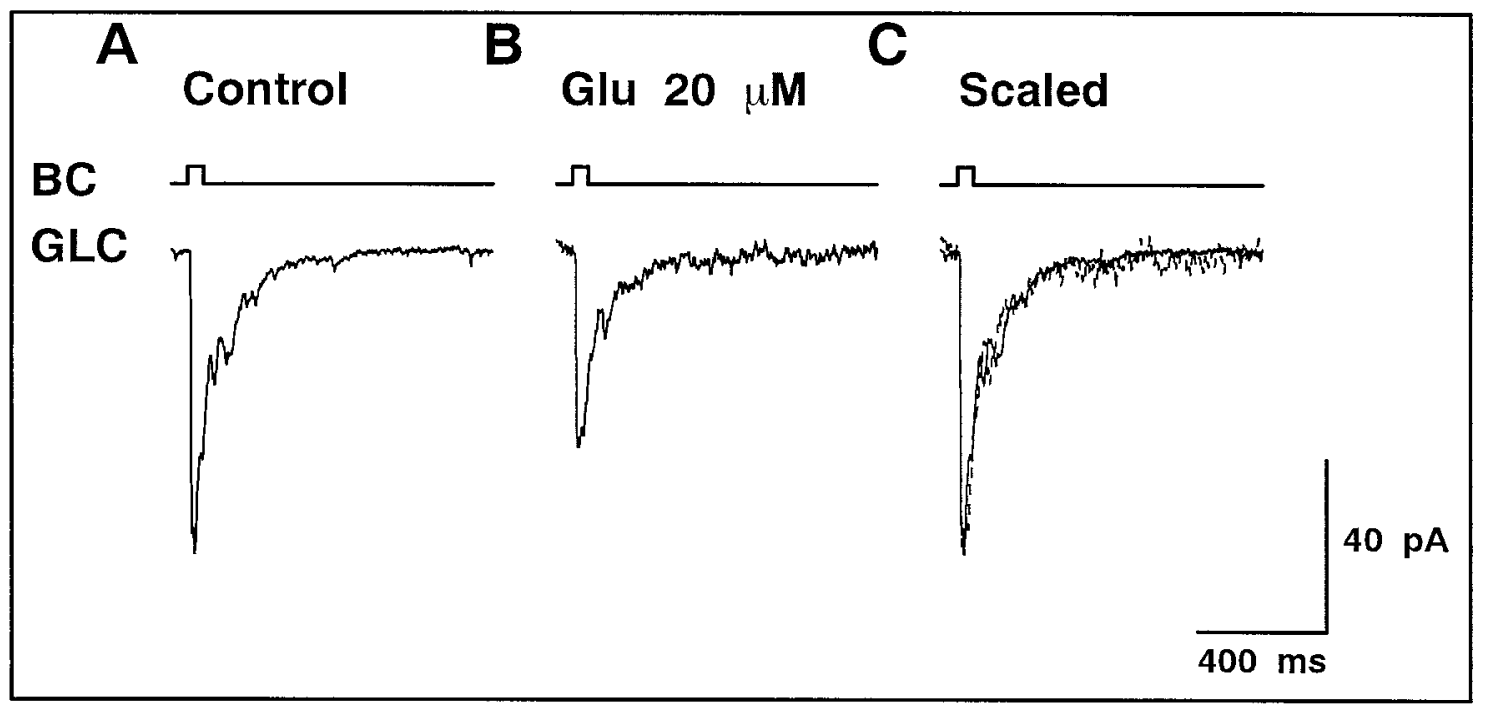

Figure 6. Elevation of the ambient glutamate concentration did not prolong the evoked non-NMDA-EPSC. $A$, BC was depolarized from -68 to $-8 \mathrm{mV}$ for $50 \mathrm{msec}$, and the evoked non-NMDA-EPSC was recorded from GLC voltage-clamped at $-80 \mathrm{mV}$. Activation of NMDA receptors was blocked by $50 \mu \mathrm{M}$ D-AP-5 in the bath solution. $B$, Addition of $20 \mu \mathrm{M}$ glutamate to the bath solution reduced the amplitude of the evoked non-NMDA-EPSC. $C$, After scaling of the trace shown in $B$ (dotted trace), both current traces were superimposable.

prolonged (Fig. 5A, thick line). The evoked EPSC in the presence of PDC was blocked entirely with addition of CNQX $(10 \mu \mathrm{M})$ to the superfusate (data not shown), indicating that the evoked EPSC was generated only by the activation of non-NMDA receptors.

The ratio of the peak amplitude before and after the application of PDC varied among cell pairs $(1.13 \pm 0.13$ of control; $n=$ 6) (Fig. $5 B)$, but the ratio of the total charge $(2.93 \pm 0.44$ of control) was always larger than that of the peak amplitude. The half-decay time of non-NMDA-EPSC also prolonged significantly in the presence of PDC (control, $15.7 \pm 2.9 \mathrm{msec}$; PDC, $25.7 \pm 6.1$ msec; $p=0.04$ ) (Fig. 5C).

We examined the effect of another type of glutamate uptake inhibitor, THA, on the evoked non-NMDA-EPSC of GLCs. THA is a substrate of glutamate transporters with a broad spectrum; it is "aspartate-like" in length but is less conformationally constrained than PDC (Bridges et al., 1991). THA has been reported to suppress the glutamate uptake current in Müller cells isolated from the tiger salamander retina (Barbour et al., 1991). We confirmed that the evoked non-NMDA-EPSC in the GLC was prolonged by application of THA $(100 \mu \mathrm{M})$. The peak amplitude and total charge of the evoked non-NMDA-EPSC changed to $0.84 \pm 0.12$ and $4.68 \pm 1.86(n=3)$ of control, respectively (data not shown).

These results indicate that glutamate uptake plays an active role in shaping the non-NMDA-EPSC in GLCs that is evoked by a single depolarizing pulse applied to a BC. However, we could not distinguish whether the shaping of the EPSC was caused by the actual uptake of glutamate by transporters or by the mere binding of glutamate to transporters without translocation (Diamond and Jahr, 1997). In the tiger salamander retina, it has been demonstrated that there are five distinct subtypes of glutamate transporters and that multiple subtypes coexist in a single Müller cell, as well as in a single neuron (Eliasof et al., 1998). Because subtype-specific blockers of glutamate transporters are not available, we could not determine which type of cells and which subtype of glutamate transporters were responsible for the clearance of glutamate from the IPL of the newt retina.

\section{Suppression of the evoked non-NMDA-EPSC by tonic elevation of ambient glutamate concentration}

Inhibition of the glutamate uptake may cause tonic accumulation of released glutamate in the synaptic cleft, which would change the state of presynaptic and/or postsynaptic glutamate receptors. Prolongation of EPSCs might be caused by such a side effect on glutamate receptors. This possibility was investigated by treating the slice preparation with exogenously applied glutamate (20-100 $\mu \mathrm{M})$ to raise the ambient glutamate concentration tonically without applying PDC. The glutamate concentration in the synaptic cleft should be lower than that in the bath solution because of the glutamate uptake. D-AP-5 was applied to isolate the non-NMDA component of the evoked EPSC.

A raise in glutamate concentration in the superfusate resulted in the decrease of both the peak amplitude and total charge of the evoked non-NMDA-EPSC (Fig. 6B). With application of $20 \mu \mathrm{M}$ glutamate, the peak amplitude and total charge decreased to $0.68 \pm 0.09$ and $0.52 \pm 0.15(n=5)$ of control, respectively. The shape of the non-NMDA-EPSC was not affected by $20 \mu \mathrm{M}$ glutamate (Fig. 6C). With higher concentrations of glutamate, the evoked non-NMDA-EPSC decayed rapidly (data not shown). The effects of glutamate were readily reversible after washout. Because tonic elevation of the ambient glutamate concentration suppressed the amplitude of the evoked non-NMDA-EPSC but never prolonged its time course, it is clear that prolongation of the evoked non-NMDA-EPSC by PDC (Fig. 5) cannot be ascribed simply to the tonic accumulation of glutamate. In the present study, we did not further analyze the mechanisms by which the ambient glutamate suppressed the evoked non-NMDA-EPSC (Zorumski et al., 1996).

\section{No effect of PDC on spontaneous EPSCs}

It has been demonstrated that spontaneous EPSCs in GLCs are mediated solely by the activation of non-NMDA receptors (Taylor et al., 1995; Matsui et al., 1998). We examined whether PDC prolonged spontaneous EPSCs, similar to the evoked non-NMDA-EPSC.

At the holding potential of $-80 \mathrm{mV}$, the mean peak amplitude 


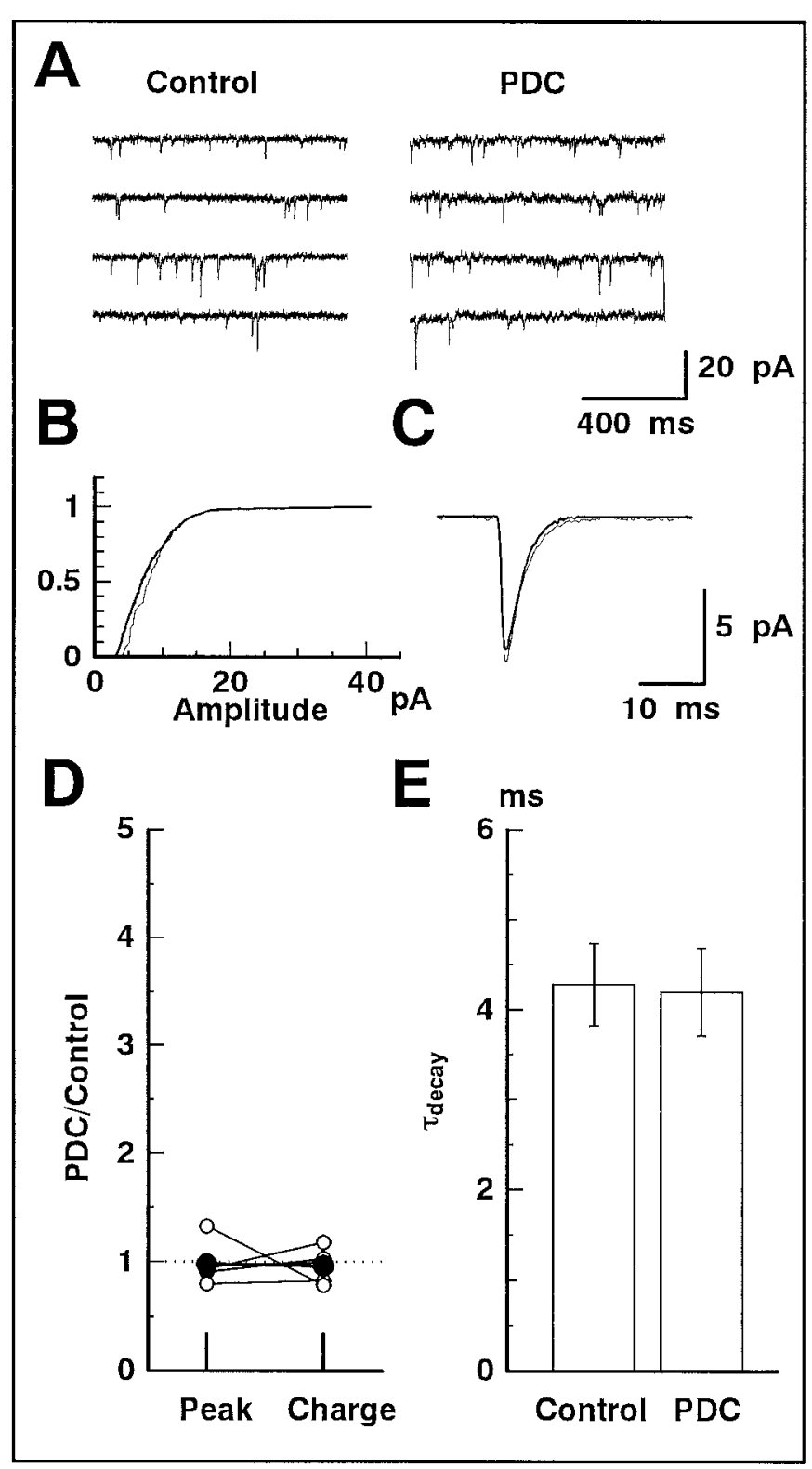

Figure 7. Spontaneous EPSCs were not affected by PDC. $A$, The membrane current was recorded continuously (4 sec records are displayed) from a GLC voltage-clamped at $-80 \mathrm{mV}$. Spontaneous EPSCs were clearly observed. The slice preparation was superfused with the solution containing D-AP-5 $(50 \mu \mathrm{M}$; Control $)$ and then with the solution containing D-AP-5 and PDC (200 $\mu \mathrm{M}) . B$, The cumulative amplitude distribution of spontaneous EPSCs obtained in the absence (thick line) and presence (thin line) of PDC. $C$, The waveforms of the averaged spontaneous EPSCs in the absence (thick line) and presence (thin line) of PDC. $D$, Relative changes of the peak amplitude and total charge of the averaged spontaneous EPSCs in the absence and presence of PDC $(n=5)$. The averaged values of five data are shown by large filled circles. $E$, The decay phase of the averaged spontaneous EPSC was well fitted by a single exponential function. The time constant of the decay $\left(\tau_{\text {decay }}\right)$ was not affected by PDC. Data were obtained from five cells.

of the spontaneous discrete events (spontaneous EPSCs) was $6.6 \pm 2.2 \mathrm{pA}$ (five cells). In the presence of $50 \mu \mathrm{M} \mathrm{D}-\mathrm{AP}-5$, application of PDC slightly increased the inward holding current at $-80 \mathrm{mV}(4.6 \pm 1.0 \mathrm{pA} ; n=28)$ and baseline fluctuations (Fig. $7 A$ ). Addition of $5 \mu \mathrm{M} \mathrm{NBQX}$ could suppress the increased holding current and baseline fluctuations. Thus, the increase in the holding current and baseline fluctuations is probably induced by the activation of non-NMDA receptors of GLCs by elevated ambient glutamate.

PDC $(200 \mu \mathrm{M})$ did not affect the frequency of spontaneous EPSCs significantly (control, $3.3 \pm 0.6 \mathrm{~Hz}$; PDC, $3.0 \pm 0.4 \mathrm{~Hz}$; $n=5 ; p=0.69$ ). The cumulative amplitude distribution remained nearly the same (Fig. $7 B$ ). Small events may have been slightly obscured by the increased baseline fluctuations in the presence of PDC. Nonoverlapping events were isolated, aligned at the rising phase of $50 \%$ amplitude of the peak, and averaged for each condition. The two traces could be superimposed (Fig. 7C). Neither the peak amplitude $(0.98 \pm 0.09$ of control $)$ nor the total charge $(0.96 \pm 0.07$ of control) of the average waveform of spontaneous EPSCs was affected by the application of PDC in all cells analyzed (five cells) (Fig. 7D). The decay of spontaneous EPSCs was well fitted by a single exponential function (Taylor et al., 1995; Matsui et al., 1998), and the time constant did not change significantly after application of PDC (control, $4.3 \pm 0.5$ msec; PDC, $4.2 \pm 0.5 \mathrm{msec} ; n=5 ; p=0.86$ ).

The uptake inhibitor PDC prolonged the decay time course of the evoked non-NMDA-EPSC but not spontaneous EPSCs. This suggests that, when only a few synaptic vesicles are fused to the presynaptic plasma membrane of $\mathrm{BC}$, as is the case of spontaneous EPSCs, passive diffusion may be sufficiently fast in removing glutamate from the synaptic cleft. On the other hand, when multiple synaptic vesicles are fused simultaneously or in close succession, as is the case of the evoked EPSC, a significant amount of glutamate may accumulate in the extracellular space. In this situation, passive diff usion may take a long time to extrude glutamate, and thus glutamate transporters may play an active role in removing glutamate from the synaptic cleft, contributing to rapid termination of the evoked non-NMDA-EPSC.

\section{Prolongation of the evoked NMDA-EPSC by PDC}

Non-NMDA receptors mediate the early component of the evoked EPSC, whereas NMDA receptors mediate its late component in GLCs of the newt retina (Matsui et al., 1998). The NMDA component increases with increasing duration of depolarizing pulses given to a $\mathrm{BC}$. We have proposed that non-NMDA receptors are located at the postsynaptic region immediately beneath each release site, whereas NMDA receptors are located slightly away from that region. Because PDC prolonged the evoked non-NMDA-EPSC seen above, it seemed natural to assume that the evoked NMDA-EPSC was also affected by PDC. This prediction was further reinforced by the fact that NMDA receptors have considerably higher affinity for glutamate than non-NMDA receptors (Patneau and Mayer, 1990) and are better suited for detection of a low level of glutamate.

Bridges et al. (1991) reported that PDC not only inhibits the glutamate uptake but also weakly interacts with NMDA receptors. Therefore, we first examined whether PDC has any effect on the NMDA receptor-mediated current in spiking neurons isolated from the newt retina. NBQX $(5 \mu \mathrm{M})$, glycine $(10 \mu \mathrm{M})$, and strychnine $(10 \mu \mathrm{M})$ were included in both the superfusate and the puff pipette solution to block non-NMDA receptors, to potentiate NMDA receptors (Johnson and Ascher, 1987) and to inhibit activation of glycine receptors, respectively. Brief puff application of $200 \mu \mathrm{M}$ glutamate produced an inward current in a spiking neuron maintained at $-40 \mathrm{mV}$ (Fig. $8 A$ ). Application of PDC reduced the amplitude of the glutamate-induced current to $0.48 \pm 0.05(n=5)$ of control, without changing its time course 


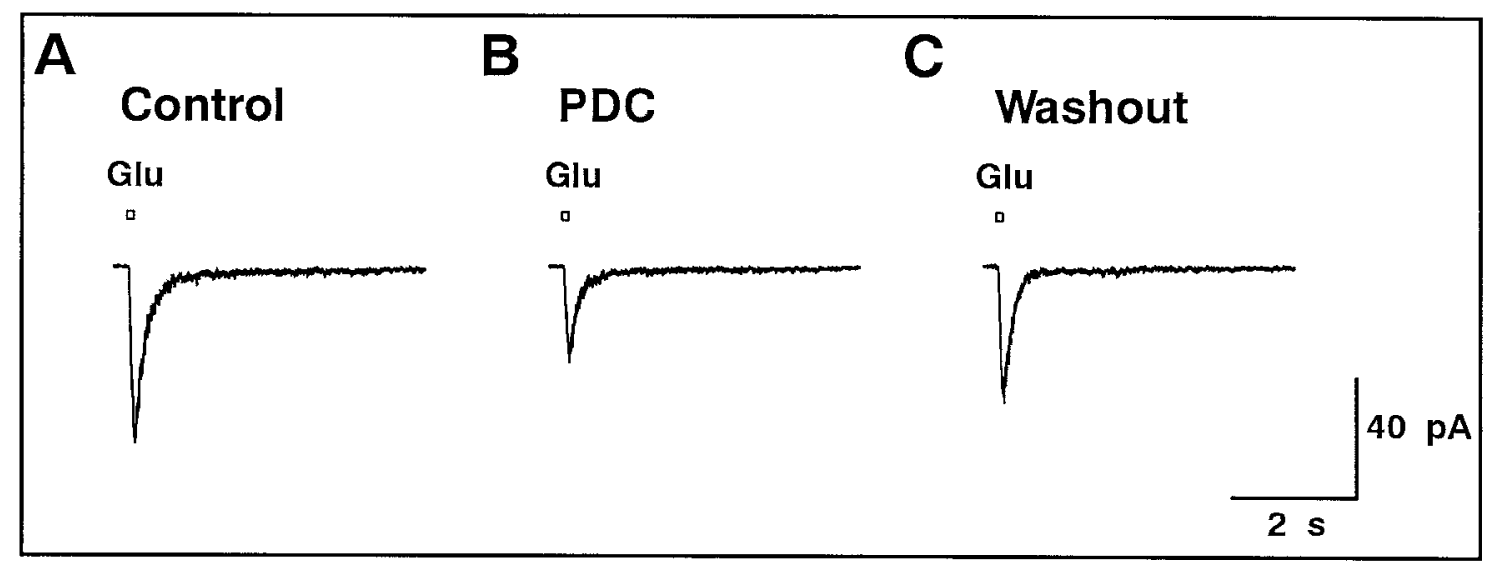

Figure 8. Effect of PDC on the NMDA receptor-mediated current in an isolated spiking neuron. A, A 100 msec puff (top) of glutamate (200 $\mu \mathrm{M})$ evoked an inward current in an isolated spiking neuron voltage-clamped at $-40 \mathrm{mV}$. Both the superfusate and the puff pipette solution included $5 \mu \mathrm{M}$ NBQX, $10 \mu \mathrm{M}$ glycine, and $10 \mu \mathrm{M}$ strychnine. $B$, Bath application of PDC (200 $\mu \mathrm{M})$ reduced the amplitude of the glutamate-induced current. $C$, The suppressive effect of PDC reversed after washout.

(Fig. 8B). The suppression was reversible after washout (Fig. 8C). The glutamate-induced current was completely abolished with addition of $50 \mu \mathrm{M}$ D-AP-5 in the superfusate (data not shown). Because PDC partially suppresses the NMDA receptor-mediated current in isolated spiking neurons, caution was taken in evaluating the effect of PDC on the evoked NMDA-EPSC.

$I_{\mathrm{Ca}}$ and the evoked NMDA-EPSC were recorded simultaneously from a pair of BC and GLC in the slice preparation. The slice preparation was superfused with the solution containing 5 $\mu \mathrm{M}$ NBQX to block the non-NMDA receptors. The membrane potential of the GLC was maintained at $-40 \mathrm{mV}$ to relieve the $\mathrm{Mg}^{2+}$ block of NMDA receptors (Matsui et al., 1998, their Fig. 4). PDC $(200 \mu \mathrm{M})$ had no effect on $I_{\mathrm{Ca}}$ in the BC, whereas the evoked NMDA-EPSC in the GLC was significantly prolonged (Fig. 9A). The ratio of the peak amplitude with and without PDC did not change significantly $(0.98 \pm 0.09$ of control; $n=4)$, but the ratio of the total charge with and without PDC always increased $(2.52 \pm 0.47$ of control; $n=4)$. The relationship shown in Figure $9 B$ is similar to that illustrated in Figure $5 B$ in which the evoked non-NMDA-EPSC was examined. The half-decay time was increased significantly from $18.5 \pm 3.6$ (control) to $32.5 \pm 6.7 \mathrm{msec}$ (PDC) $(n=4 ; p=0.04)$ (Fig. 9C). Further addition of $50 \mu \mathrm{M}$ D-AP-5 blocked the evoked NMDA-EPSC completely $(n=3$; data not shown).

Application of PDC in the presence of NBQX induced a small inward shift of the holding current $(1.8 \pm 1.6 \mathrm{pA}$ at $-40 \mathrm{mV} ; n=$ 7), which was suppressed with addition of $50 \mu \mathrm{M}$ D-AP-5. This increase in the holding current is probably caused by the activation of NMDA receptors by elevated ambient glutamate. It would be interesting to see whether the application of PDC without blockers of ionotropic glutamate receptors (NBQX and D-AP-5) would newly uncover the NMDA component of spontaneous EPSCs, which was never detected with intact glutamate transporters. However, without blockers of glutamate receptors, the holding current largely fluctuated after application of PDC, making it difficult to reliably isolate the small spontaneous events.

PDC directly reduced the amplitude of the glutamate-induced current through NMDA receptors in isolated spiking neurons (Fig. 8B). However, the evoked NMDA-EPSC did not change significantly in amplitude and was obviously prolonged in duration after application of PDC (Fig. 9B). These results indicate that the effect of PDC on glutamate transporters overwhelmed its direct effect on postsynaptic NMDA receptors. The enhancement of the evoked NMDA-EPSC further supports the idea that inhibition of glutamate uptake induces the accumulation of glutamate in the synaptic cleft and slows the clearance of glutamate.

\section{DISCUSSION}

The effect of PDC was to slow the clearance of glutamate from the synaptic cleft

We found that $200 \mu \mathrm{M}$ PDC effectively reduced the glutamateinduced uptake current in Müller cells isolated from the newt retina (Fig. 1). PDC at this concentration did not affect postsynaptic non-NMDA receptor-mediated current of isolated spiking neurons (Fig. 2). However, the evoked non-NMDA-EPSC was prolonged by PDC (Fig. 5). The evoked NMDA-EPSC was also enhanced by PDC, although PDC suppressed partially the current through NMDA receptors (Fig. 8). These results indicate that the release-triggered transient glutamate increase in the synaptic cleft is prolonged after inhibition of the glutamate uptake by PDC.

\section{PDC may not affect presynaptically}

We cannot exclude the possibility that PDC may affect presynaptic BCs. However, it seems unlikely that the prolongation of the evoked EPSCs would be ascribed only to the presynaptic influence. First, PDC affected neither the time course nor the amplitude of $I_{\mathrm{Ca}}$ in BCs, which triggers and controls transmitter release (Figs. 5, 9). PDC did not shift the $I_{\mathrm{Ca}}-V$ relationship to either side along the voltage axis (data not shown). Second, PDC did not change the frequency of spontaneous EPSCs consistently (Fig. 7). The change in the frequency of spontaneous EPSCs is often used as a measure of changes in release probability. Third, we used THA, another type of uptake inhibitor, and found that it had similar effects on the evoked EPSCs as PDC (see Results). This observation indicates that prolongation of the evoked EPSCs is not attributable to nonspecific actions of PDC. Fourth, we measured membrane capacitance increase associated with exocytosis using axon terminals of ON-type bipolar cells isolated from the goldfish retina and found that the amplitude of membrane capacitance changes was not affected significantly by PDC (depolarization from -70 to $-10 \mathrm{mV}$ for $50 \mathrm{msec} ; 46.5 \pm 7.0 \mathrm{fF}$ in control; $43.8 \pm 7.9 \mathrm{fF}$ with PDC; $n=4 ; p=0.27$ ) (our unpublished 


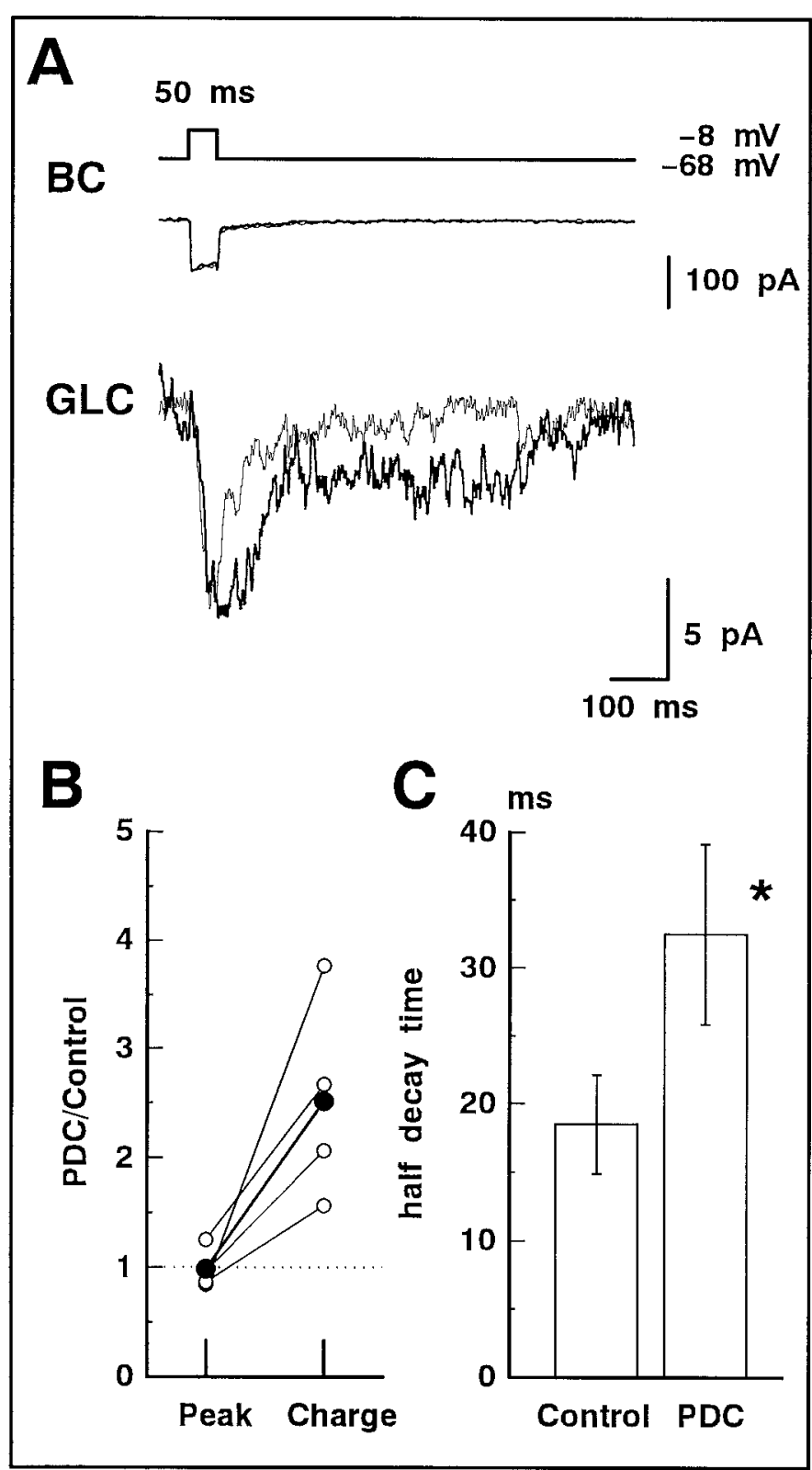

Figure 9. The evoked NMDA-EPSC was prolonged by PDC. $A$, In the slice preparation, dual whole-cell recordings were performed. A $50 \mathrm{msec}$ depolarizing pulse (from -68 to $-8 \mathrm{mV}$; top) applied to $\mathrm{BC}$ activated $I_{\mathrm{Ca}}$ (middle; thin trace) in BC and evoked the NMDA-EPSC in GLC voltageclamped at $-40 \mathrm{mV}$ (bottom; thin trace). Bath application of $200 \mu \mathrm{M}$ PDC did not change $I_{\mathrm{Ca}}$ (middle; thick trace) but prolonged the evoked NMDAEPSC (bottom; thick trace). The superfusate always contained $5 \mu \mathrm{M}$ NBQX. B, Relative increase in the peak amplitude (Peak) and total charge (Charge) of the evoked NMDA-EPSC before (Control) and after application of PDC $(n=4)$. The averaged values are shown by large filled circles. $C$, The half-decay time of the evoked NMDA-EPSC in the absence (Control) and presence of PDC.

observations). This evidence is rather indirect because $\mathrm{BC}$ terminals were obtained from different species, but goldfish BC terminals are the only preparation among retinal BCs that allow direct capacitance measurements to this date.

PDC might work indirectly on presynaptic terminals of $\mathrm{BC}$; inhibition of glutamate uptake increases ambient glutamate concentration, which may in turn activate the presynaptic metabo- tropic glutamate receptors. However, in cultured hippocampal neurons, an increase in ambient glutamate concentration decreases presynaptic transmitter release (Maki et al., 1994; Zorumski et al., 1996).

\section{The effect of tonic increase in ambient glutamate on postsynaptic non-NMDA receptors}

Inhibition of glutamate uptake with PDC in the presence of D-AP-5 induced a small steady inward current, which could be attributable to glutamate accumulation (Isaacson and Nicoll, 1993). Because neither the amplitude nor the shape of spontaneous EPSCs was affected by PDC (Fig. 7), it was suggested that the rise in ambient glutamate was not high enough to substantially alter the kinetics of non-NMDA receptors. Bath application of glutamate without PDC to the slice preparation reduced the peak amplitude and total charge of the evoked non-NMDA-EPSC (Fig. 6). Therefore, even if inhibition of glutamate uptake resulted in a buildup of ambient glutamate, this could not explain the PDC-induced prolongation of the evoked non-NMDA-EPSC.

It is interesting to estimate the glutamate concentration at the synaptic sites when $20 \mu \mathrm{M}$ glutamate was bath applied to the slice preparation (Fig. 6). In microcultures of hippocampal neurons, 20 $\mu \mathrm{M}$ glutamate was high enough to completely abolish the excitatory autaptic current (Zorumski et al., 1996). In the tiger salamander retina, the dose (glutamate)-response curve obtained in isolated horizontal cells was shifted to a lower range along the concentration axis than that obtained in horizontal cells of the slice preparation, even in the presence of glutamate uptake inhibitor (Gaal et al., 1998). Based on the data of Gaal et al., 1998 (their Fig. 2), it can be assumed that $20 \mu \mathrm{M}$ glutamate applied to the slice preparation in the presence of glutamate uptake inhibitor would be reduced to $\sim 10 \mu \mathrm{M}$ at the synaptic sites. In the present experiment shown in Figure 6 in which glutamate uptake inhibitor was not applied, the glutamate concentration at the synaptic sites would be lowered further (less than $\sim 10 \mu \mathrm{M}$ ). Non-NMDA receptors in patch membranes excised from area CA1 pyramidal cells are half desensitized at $4.2 \mu \mathrm{M}$ of glutamate (Colquhoun et al., 1992). Because the amplitude of the evoked non-NMDA-EPSC was nearly halved by bath-applied $20 \mu \mathrm{M}$ glutamate (Fig. 6), we estimate that the effective glutamate concentration at the synaptic site was probably as low as $\sim 4 \mu \mathrm{M}$.

\section{Factors that determine the shape of spontaneous and evoked EPSCs}

The time course of spontaneous EPSCs was not affected by the application of PDC (Fig. 7). It seems possible that the glutamate transient induced by the fusion of a single synaptic vesicle may be slightly prolonged by PDC (Tong and Jahr, 1994). However, such prolongation of the glutamate transient may not be sufficient enough to affect the decay of spontaneous EPSCs, which is probably determined by the kinetics of non-NMDA receptors (Diamond and Jahr, 1997).

The evoked EPSCs (both non-NMDA- and NMDA-EPSCs) were obviously prolonged by PDC (Figs. 5, 9). Multiple fusion of synaptic vesicles must have occurred when the $\mathrm{BC}$ was stimulated with single depolarizing pulses. Because the total charge of the evoked EPSC increases as the pulse duration is increased (Matsui et al., 1998), fusion of synaptic vesicles is not locked to the onset of depolarization but continues during depolarization. It has been suggested in goldfish retinal BCs that fusion of synaptic vesicles continues at a high rate for $\sim 200 \mathrm{msec}$ after the onset of depolarization (von Gersdorff and Matthews, 1994; Sakaba et al., 
1997). These results indicate that a large amount of transmitter is released during depolarization of a single $\mathrm{BC}$ and must accumulate in the synaptic cleft. In addition, transmitters released from multiple active zones of a single BC may cause "cross-talk" among clusters of postsynaptic receptors in a GLC. Therefore, released glutamate may stay for a long period if glutamate is extruded from the synaptic cleft only by passive diffusion. The present results indicate that glutamate uptake must play an important role in determining the time course of the evoked EPSCs.

Based on the values of $K_{\mathrm{Glu}}$ and $K_{\mathrm{PDC}}$ obtained from the isolated Müller cells (Fig. 1), it is estimated that the uptake rate of $1 \mathrm{~mm}$ glutamate (the estimated peak concentration of the glutamate transient induced by a presynaptic spike) (Clements et al., 1992) is reduced to $88.6 \%$ in the presence of $200 \mu \mathrm{M}$ PDC. The effective concentration of PDC at the synaptic site should be lower than $200 \mu \mathrm{M}$ because PDC itself is taken up by glutamate transporters. Thus, the rate of the glutamate uptake would be reduced only slightly. However, a small change in the uptake rate induced by bath-applied $200 \mu \mathrm{M}$ PDC was effective in significantly altering the time course of the evoked non-NMDA-EPSC (Fig. 5 ). We should consider a spatial gradient of glutamate in the synaptic cleft: high at the release site and low at regions away from the release site. Inhibition of glutamate uptake by PDC is more effective at lower glutamate concentrations (Fig. 1F). Therefore, it is likely that at least part of the decay phase of the evoked non-NMDA-EPSC may be shaped by the non-NMDA receptors experiencing relatively low concentrations of glutamate at which PDC is more effective (i.e., the non-NMDA receptors at peripheral regions of the synaptic cleft).

Using cyclothiazide (CTZ), a pharmacological agent that slows desensitization of non-NMDA receptors, we have demonstrated that rapid desensitization of non-NMDA receptors greatly shapes the decay phase of the evoked non-NMDA-EPSC (Matsui et al., 1998). However, in the present experiment, we found that inhibition of the glutamate uptake prolonged the evoked nonNMDA-EPSC without applying CTZ. This indicates that the shape of the evoked non-NMDA-EPSC is not exclusively determined by receptor desensitization. The time course of glutamate release, receptor desensitization, and uptake all contribute to the shaping of the evoked non-NMDA-EPSC in the inner retina.

\section{Graded synaptic transmission versus spike-triggered synaptic transmission}

It is interesting to compare the present results obtained from nonspiking, graded synaptic transmission in the inner retina with those from spike-triggered synaptic transmission. Isaacson and Nicoll (1993) recorded from pyramidal cells in area CA1 of the hippocampal slice and reported that an uptake inhibitor fails to alter the kinetics of the EPSC. They have suggested that glutamate is rapidly cleared from the synaptic cleft by diffusion. Mennerick and Zorumski (1994) have reported in microcultured single neurons that prolongation of postsynaptic current by uptake inhibitor is only visible in the presence of CTZ. Otis et al. (1996) have reported in calyceal somatic synapse made in chick nucleus magnocellularis that uptake inhibitors selectively enhance the slower phase of EPSC. These different views seem to arise from variations in physiological and morphological features of synapses. These features may be differentiated and selected for appropriate functioning of each CNS synapse.

\section{Addendum}

After this paper had been submitted for publication, Higgs and Lukasiewicz (1999) reported the contribution of glutamate trans- porters to synaptic transmission in the tiger salamander retina. They stimulated multiple BCs extracellularly and observed prolongation of EPSCs recorded from ganglion cells with application of uptake inhibitors. Using double patch recordings from $\mathrm{BC}$ and GLC pairs, we support their conclusions, and furthermore we demonstrate the active role of transporters in clearance of released glutamate from the synaptic cleft.

\section{REFERENCES}

Ball AK, Dickson DH (1983) Displaced amacrine and ganglion cells in the newt retina. Exp Eye Res 36:199-213.

Barbour B, Brew H, Attwell D (1991) Electrogenic uptake of glutamate and aspartate into glial cells isolated from the salamander (Ambystoma) retina. J Physiol (Lond) 436:169-193.

Brew H, Attwell D (1987) Electrogenic glutamate uptake is a major current carrier in the membrane of axolotl retinal glial cells. Nature 327:707-709.

Bridges RJ, Stanley MS, Anderson MW, Cotman CW, Chamberlin AR (1991) Conformationally defined neurotransmitter analogues. Selective inhibition of glutamate uptake by one pyrrolidine-2:4-dicarboxylate diastereomer. J Med Chem 34:717-725.

Clements JD (1996) Transmitter timecourse in the synaptic cleft: its role in central synaptic function. Trends Neurosci 19:163-171.

Clements JD, Lester RAJ, Tong G, Jahr CE, Westbrook GL (1992) The time course of glutamate in the synaptic cleft. Science 258:1498-1501.

Colquhoun D, Jonas P, Sakmann B (1992) Action of brief pulses of glutamate on AMPA/kainate receptors in patches from different neurones of rat hippocampal slices. J Physiol (Lond) 458:261-287.

Diamond JS, Jahr CE (1995) Asynchronous release of synaptic vesicles determines the time course of the AMPA receptor-mediated EPSC. Neuron 15:1097-1107.

Diamond JS, Jahr DE (1997) Transporters buffer synaptically released glutamate on a submillisecond time scale. J Neurosci 17:4672-4687.

Dowling J (1987) The retina, an approachable part of the brain. Boston: Harvard UP

Eliasof S, Arriza JL, Leighton BH, Kavanaugh MP, Amara SG (1998) Excitatory amino acid transporters of the salamander retina: identification, localization, and function. J Neurosci 18:698-712.

Gaal L, Roska B, Picaud SA, Wu SM, Marc R, Werblin FS (1998) Postsynaptic response kinetics are controlled by a glutamate transporter at cone photoreceptors. J Neurophysiol 79:190-196.

Harada T, Harada C, Watanabe M, Inoue Y, Sakagawa T, Nakayama N, Sasaki S, Okuyama S, Watase K, Wada K, Tanaka K (1998) Functions of the two glutamate transporters GLAST and GLT-1 in the retina. Proc Natl Acad Sci USA 95:4663-4666.

Higgs MH, Lukasiewicz PD (1999) Glutamate uptake limits synaptic excitation of retinal ganglion cells. J Neurosci 19:3691-3700.

Isaacson JS, Nicoll RA (1993) The uptake inhibitor 1-trans-PDC enhances responses to glutamate but fails to alter the kinetics of excitatory synaptic currents in the hippocampus. J Neurophysiol 70:2187-2191.

Johnson JW, Ascher P (1987) Glycine potentiates the NMDA response in cultured mouse brain neurons. Nature 325:529-531.

Jones MV, Westbrook GL (1996) The impact of receptor desensitization on fast synaptic transmission. Trends Neurosci 19:96-101.

Lester RAJ, Clements JD, Westbrook GL, Jahr CE (1990) Channel kinetics determine the time course of NMDA receptor-mediated synaptic currents. Nature 346:565-567.

Maki R, Robinson MB, Dichter MA (1994) The glutamate uptake inhibitor 1-trans-pyrrolidine-2,4-dicarboxylate depresses excitatory synaptic transmission via a presynaptic mechanism in cultured hippocampal neurons. J Neurosci 14:6754-6762.

Matsui K, Hosoi N, Tachibana M (1998) Excitatory synaptic transmission in the inner retina: paired recordings of bipolar cells and neurons of the ganglion cell layer. J Neurosci 18:4500-4510.

Mennerick S, Zorumski CF (1994) Glial contribution to excitatory neurotransmission in cultured hippocampal cells. Nature 368:59-62.

Minami N, Berglund K, Sakaba T, Tachibana M (1998) Potentiation of transmitter release by protein kinase $\mathrm{C}$ in goldfish retinal bipolar cells. J Physiol (Lond) 512:219-225.

Mittman S, Taylor WR, Copenhagen DR (1990) Concomitant activation of two types of glutamate receptor mediates excitation of salamander retinal ganglion cells. J Physiol (Lond) 428:175-197. 
Nowak L, Bregestovski P, Ascher P, Herbet A, Prochiantz A (1984) Magnesium gates glutamate-activated channels in mouse central neurones. Nature 307:462-465.

Otis TS, Wu Y-C, Trussell LO (1996) Delayed clearance of transmitter and the role of glutamate transporters at synapses with multiple release sites. J Neurosci 16:1634-1644.

Patneau DK, Mayer ML (1990) Structure-activity relationships for amino acid transmitter candidates acting at $N$-methyl-D-aspartate and quisqualate receptors. J Neurosci 10:2385-2399.

Rauen T, Taylor WR, Kuhlbrodt K, Wiessner M (1998) High-affinity glutamate transporters in the rat retina: a major role of the glial glutamate transporter GLAST-1 in transmitter clearance. Cell Tissue Res 291:19-31.

Saito T, Kujiraoka T (1982) Physiological and morphological identification of two types of on-center bipolar cells in the carp retina. J Comp Neurol 205:161-170.

Sakaba T, Tachibana M, Matsui K, Minami N (1997) Two components of transmitter release in retinal bipolar cells: exocytosis and mobilization of synaptic vesicles. Neurosci Res 27:357-370.

Sarantis M, Ballerini L, Miller B, Silver RA, Edwards M, Attwell D (1993) Glutamate uptake from the synaptic cleft does not shape the decay of the non-NMDA component of the synaptic current. Neuron 11:541-549.

Schwartz EA, Tachibana M (1990) Electrophysiology of glutamate and sodium co-transport in a glial cell of the salamander retina. J Physiol (Lond) 426:43-80.

Suzuki S, Tachibana M, Kaneko A (1990) Effects of glycine and GABA on isolated bipolar cells of the mouse retina. J Physiol (Lond) 421:645-662.

Tachibana M, Okada T (1991) Release of endogenous excitatory amino acids from ON-type bipolar cells isolated from the goldfish retina. J Neurosci 11:2199-2208.

Taylor WR, Chen E, Copenhagen DR (1995) Characterization of spontaneous excitatory synaptic currents in salamander retinal ganglion cells. J Physiol (Lond) 486:207-221.

Tong G, Jahr CE (1994) Block of glutamate transporters potentiates postsynaptic excitation. Neuron 13:1195-1203.

von Gersdorff H, Matthews G (1994) Dynamics of synaptic vesicle fusion and membrane retrieval in synaptic terminals. Nature 367:735-739.

Zorumski CF, Mennerick S, Que J (1996) Modulation of excitatory synaptic transmission by low concentrations of glutamate in cultured rat hippocampal neurons. J Physiol (Lond) 494:465-477. 